\title{
Cellulase activity mapping of Trichoderma reesei cultivated in sugar mixtures under fed-batch conditions
}

\author{
Etienne Jourdier ${ }^{1 *}$, Céline Cohen ${ }^{1}$, Laurent Poughon ${ }^{2}$, Christian Larroche $^{2}$, Frédéric Monot ${ }^{1}$ \\ and Fadhel Ben Chaabane ${ }^{1}$
}

\begin{abstract}
Background: On-site cellulase production using locally available lignocellulosic biomass (LCB) is essential for cost-effective production of $2^{\text {nd }}$-generation biofuels. Cellulolytic enzymes (cellulases and hemicellulases) must be produced in fed-batch mode in order to obtain high productivity and yield. To date, the impact of the sugar composition of LCB hydrolysates on cellulolytic enzyme secretion has not been thoroughly investigated in industrial conditions.

Results: The effect of sugar mixtures (glucose, xylose, inducer) on the secretion of cellulolytic enzymes by a glucose-derepressed and cellulase-hyperproducing mutant strain of Trichoderma reesei (strain CL847) was studied using a small-scale protocol representative of the industrial conditions. Since production of cellulolytic enzymes is inducible by either lactose or cellobiose, two parallel mixture designs were performed separately. No significant difference between inducers was observed on cellulase secretion performance, probably because a common induction mechanism occurred under carbon flux limitation. The characteristics of the enzymatic cocktails did not correlate with productivity, but instead were rather dependent on the substrate composition. Increasing xylose content in the feed had the strongest impact. It decreased by 2 -fold cellulase, endoglucanase, and cellobiohydrolase activities and by 4-fold $\beta$-glucosidase activity. In contrast, xylanase activity was increased 6 -fold. Accordingly, simultaneous high $\beta$-glucosidase and xylanase activities in the enzymatic cocktails seemed to be incompatible. The variations in enzymatic activity were modelled and validated with four fed-batch cultures performed in bioreactors. The overall enzyme production was maintained at its highest level when substituting up to $75 \%$ of the inducer with non-inducing sugars.
\end{abstract}

Conclusions: The sugar substrate composition strongly influenced the composition of the cellulolytic cocktail secreted by T. reesei in fed-batch mode. Modelling can be used to predict cellulolytic activity based on the sugar composition of the culture-feeding solution, or to fine tune the substrate composition in order to produce a desired enzymatic cocktail.

Keywords: Trichoderma reesei, Sugar mixture, Fed-batch cultivation, Carbon flux limitation, Industrial protocol, Inducer, Cellulase, Xylanase, $\beta$-glucosidase, On-site enzyme production, Bioethanol

\section{Background}

The bioconversion of lignocellulosic biomass (LCB) into biofuels or chemicals such as bioethanol requires cellulolytic enzymes, e.g. cellulases and hemicellulases, in order to hydrolyse both cellulose and hemicellulose into their respective monomeric sugars [1]. Cellulases display three main types of enzymatic activities: endo-1,4- $\beta$-glucanases

\footnotetext{
* Correspondence: etienne.jourdier@ifpen.fr

'IFP Energies nouvelles, 1 et 4 avenue de Bois-Préau, 92852 Rueil-Malmaison, France

Full list of author information is available at the end of the article
}

cutting cellulose chains internally, exo-1,4- $\beta$-glucanases (also called cellobiohydrolases) releasing cellobiose from cellulose chains ends, and $\beta$-glucosidases hydrolysing cellobiose to glucose. Hemicellulases or newly discovered oxidative activities may also improve LCB hydrolysis [2]. Owing to its very high secretion capacity, the filamentous fungus Trichoderma reesei (teleomorph Hypocrea jecorina) has currently been used for the industrial production of cellulolytic enzymes cocktails [3].

\section{Biomed Central}

(c) 2013 Jourdier et al.; licensee BioMed Central Ltd. This is an Open Access article distributed under the terms of the Creative Commons Attribution License (http://creativecommons.org/licenses/by/2.0), which permits unrestricted use, distribution, and reproduction in any medium, provided the original work is properly cited. 


\section{Industrial aspects of cellulolytic enzymes production}

Complete cellulose hydrolysis requires substantial cellulase loadings. The supply in enzymes is therefore a key issue for industrial LCB bioconversion. Considering biofuels, on-site cellulase (and hemicellulase) production has often been regarded as an attractive way to limit cellulase production costs, avoiding purification and stabilization of the enzymes produced as well as their transportation. In addition, on-site production allows direct use of the LCB resource available locally. Even in this case, economic studies concluded that much progress was still required to decrease cellulase costs [4-6].

To jointly achieve high productivity and yield at industrial scale, the production of cellulolytic enzymes must be conducted under carbon flux limitation in either fed-batch or continuous mode $[7,8]$. Using the highly-inducing sugar lactose, the specific production rate of cellulolytic enzymes was around 2.5 fold higher under carbon flux limitation than under carbon excess [9]. Batch cultivation on cellulose could afford a satisfactory carbon flux limitation when cellulose hydrolysis was slower than sugar uptake capacity. However, kinetics of these two unitary reactions are rather complex and difficult to manage [8] as well as stirring and aeration in viscous cellulosic media. In comparison to batch cultivation, fed-batch process with soluble carbon sources has increased the final enzyme concentration by a factor of three and the corresponding productivity by a factor of four [10]. The industrial fermentation process developed by IFPEN consists in a two-phase culture including a first quick cellular growth in excess of substrate and a subsequent cellulase production performed in fed-batch mode under carbon flux limitation [11]. Mixed carbon sources like LCB hydrolysates are potentially usable [12], but their effects on productivity and characteristics of the enzymatic cocktail have never been studied in detail.

\section{Use of lignocellulosic substrates for enzyme production}

Many studies have compared the enzymatic activities produced by $T$. reesei on various substrates including pretreated cellulosic materials $([10,13,14]$ for reviews on 1980s studies and [15-21] for more recent studies). Steampretreated spruce, willow and corn stover were compared to Solka Floc cellulose: differences in specific activities were low for cellulase but significant for $\beta$-glucosidase and hemicellulase [16]. Xylanase and mannanase activities were correlated to xylan content in substrate and $\beta$-glucosidase activity was found to be 2-fold higher on lactose than on LCB substrates [19]. The induction of enzymatic activities was confirmed by the secretome analysis of cocktails produced on different substrates [17]. However, these studies were performed in batch so that the effects observed on the cocktail characteristics cannot be assuredly extrapolated to industrial fed-batch conditions.
The effect of soluble carbon sources in fed-batch or continuous cultures at the laboratory $(2 \mathrm{~L})$ and pilot (3 and $30 \mathrm{~m}^{3}$ ) scales has already been reported [11,12,22,23]. Xylose or glucose culture-feedings led to poor productions of cellulolytic enzymes [12]. The partial addition of lactose to either xylose or hemicellulose hydrolysates feeds led to high enzymes concentrations (around $30 \mathrm{~g} \mathrm{~L}^{-1}$ proteins). Compared to pure lactose feed case, concentrations in $\beta$ glucosidase and cellulase were reduced but balanced by a 5 to 10 - fold increase in xylanase [12,22]. Addition of xylose in glucose/cellobiose mixture feed improved xylanase activity [23]. The partial substitution of lactose by glucose in the feed led to higher $\beta$-glucosidase level. This effect was not confirmed when using glucose-rich hydrolysates $[11,12]$.

In literature, few cultures on three-component sugar mixtures (lactose, xylose and glucose) have been described using purified sugars. It is therefore difficult to deduce the true effect of degradation compounds, like weak organic acids, furan compounds or lignin derivatives that can be found in LCB hydrolysates.

\section{Aim of the study}

The aim of this study was to assess the effect of culture feeding-sugars on the cellulase secretion by $T$. reesei. Cultures were carried out in fed-batch mode with soluble purified carbon sources, using the hyperproducing mutant strain CL847 [24]. To ensure that results could be extrapolated, the study was performed at laboratory scale (for large screening) but under industrial-like conditions (for a valid extrapolation) The effect of sugar mixtures on productivity and cocktail characteristics was modelled. The resulting models were validated with fedbatch cultures performed in bioreactor.

\section{Results}

\section{Design of the study}

Since glucose and xylose are the main constituting monomers of LCB, they were chosen to assess the effect of sugars found in hydrolysates. Since none of them induced cellulase production by $T$. reesei, glucose and xylose mixtures were supplemented with an inducer. Lactose and cellobiose stood as candidates for induction. Lactose was not found in LCB hydrolysates whereas cellobiose might accumulate when LCB hydrolysis was incomplete. A 3factor mixture (inducer, xylose and glucose) was designed with a minimal inducer content of $8 \%$ to allow sufficient induction. To compare the respective inducing effects of lactose and cellobiose, a basal mixture design was applied twice, with lactose and with cellobiose, separately. Figure 1 shows the basal mixture design and the experimental points (fed-batch compositions) tested.

To assess the effect of sugar feed composition on both kinetics and characteristics of enzyme secretion, cellulase production was performed using a miniaturized protocol 
(thereafter called fed-flask protocol) which reproduced in flasks the behaviour of $T$. reesei in bioreactor [9]. This protocol was based on a fed-batch culture in flask with a mixed feed of carbon and nitrogen sources which enabled quasi stable culture $\mathrm{pH}$ with minimal equipment. Figure 2 shows a representative example of $\mathrm{pH}$ and protein monitoring in a fed-flask culture, compared to the bioreactor culture with identical sugar composition. Kinetics were similar with a stabilization of cell biomass after growth phase then a quasi-linear protein production of cellulolytic enzymes. Bioreactor cultivation yielded higher concentrations because of a higher oxygen transfer but the specific protein production rate was similar in both reactors [9].

\section{Reproducibility and correlations}

The first response used to characterize productivity was the mean value of the specific production rate of protein, calculated over production phase. To characterize the enzymatic cocktails produced, five enzymatic activities were measured in final media. Two of them were global activities of the whole cocktail, i.e. cellulase activity on filter paper [25] and xylanase activity on oat spelts xylan [26].

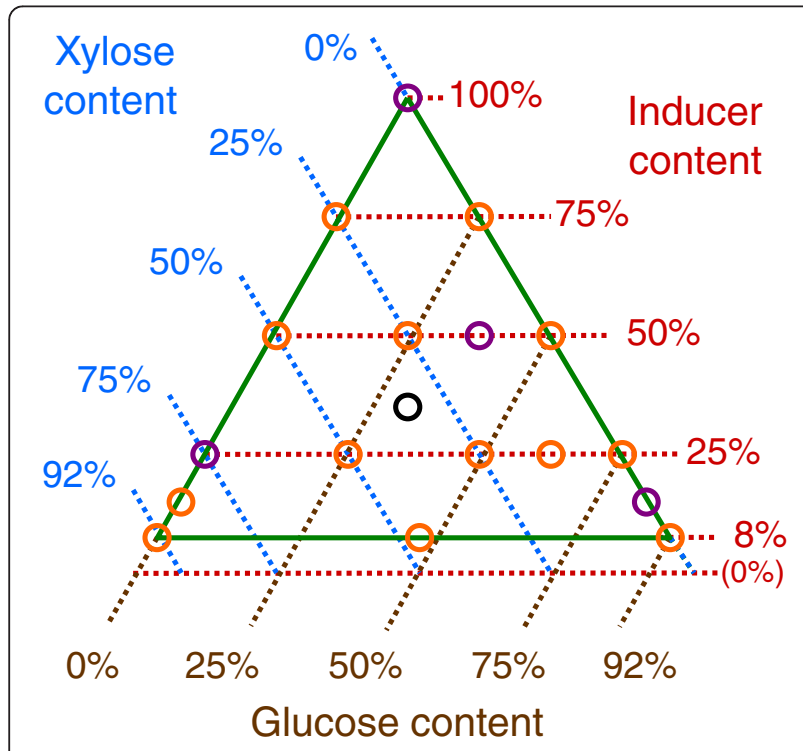

Figure 1 Schematic view of the mixture design used in the study. The effect of the feed substrate composition (in fed-batch after cell growth on glucose) was investigated with a 3-factor mixture design which can be represented in a triangle. The studied domain (in green) is defined by the factors ranges: inducer content from 8 to $100 \%$ (in red), xylose content from 0 et 92\% (in blue), glucose content from 0 to $92 \%$ (in brown). For every point in the triangle, the sum of inducer, xylose et glucose contents makes $100 \%$. Circles represent experimental points: mixtures tested in fed-flask protocol to create the models (in orange and purple), mixtures tested in bioreactor to validate the models for lactose inducer (in purple), and central point used to assess protocol reproducibility (in black). This mixture design was repeated twice: once for lactose inducer and once for cellobiose inducer.
Three of them were activities specifying the class of cellulolytic enzymes i.e. endoglucanase activity on Carboxymethyl cellulose [25], cellobiohydrolase activity due to $\mathrm{Cel} 7 \mathrm{~A} / \mathrm{CBH}$ I on $p \mathrm{NPL}$ and $\beta$-glucosidase activity on $p \mathrm{NPG}$.

With 8 runs (fed-batch mixture compositions) by series, 6 series were necessary to perform all cultivations. The reproducibility of the whole experimental design (cell growth, cellulase production in fed-flask protocol, analyses) was verified on the central point of the mixture design with lactose inducer (fed-batch containing $1 / 3$ lactose $+1 / 3$ xylose $+1 / 3$ glucose, black circle Figure 1 ), by repeating this condition 10 times ( 3 or 4 times in 3 different series). Reproducibility was satisfactory, with residual standard deviations lower than $10 \%$ for 5 of 6 enzyme activities, and $16 \%$ for xylanase activity (Table 1 ). The standard deviation of each measurement was lower than the variations observed thereafter, which validated the experimental design.

The correlations between the six responses using raw values measured in both mixture designs are shown in Figure 3. No direct correlation was found between the specific protein production rate and each specific enzymatic activity (left column Figure 3). Therefore, productivity and cocktail characteristics were two independent results in fed-batch cultures. The four individual cellulolytic activities exhibited positive correlations between each other. As already shown [25], filter paper activity resulted from the combined activities of endoglucanases, cellobiohydrolases and $\beta$-glucosidase, The highest correlation was observed between endoglucanase activity and Cel7A(CBH I) activity. In contrast, xylanase activity showed a negative correlation with the 4 other cellulolytic activities.

\section{Resulting models}

Raw values for the 6 studied responses and the 2 mixture designs were modelled as a function of the 3 factors (inducer, xylose and glucose contents) using a quadratic model:

$$
\begin{aligned}
Y= & a[\text { Ind }]+b[X y l]+c[G l u]+d[\text { Ind }][X y l] \\
& +e[\text { Ind }][G l u]+f[X y l][G l u]
\end{aligned}
$$

where [Ind], [Xyl] and [Glu] are the sugar contents (mass fraction of total sugars) for inducer, xylose and glucose respectively. When the model terms $\mathrm{d}$, e or $\mathrm{f}$ were not significant, they were removed from the model only when it increased the predicted- $\mathrm{R}^{2}$ (In Design Expert, predicted- $\mathrm{R}^{2}$ assesses the predictive capacity of a model, independently of its number of terms). The terms values and statistical analyses for the 12 models are available in Additional file 1.

All models were significant ( $\mathrm{p}$-value $<0.05)$, with predicted- $R^{2}$ between 0.45 and 0.92 (a negative predicted- $R^{2}$ 

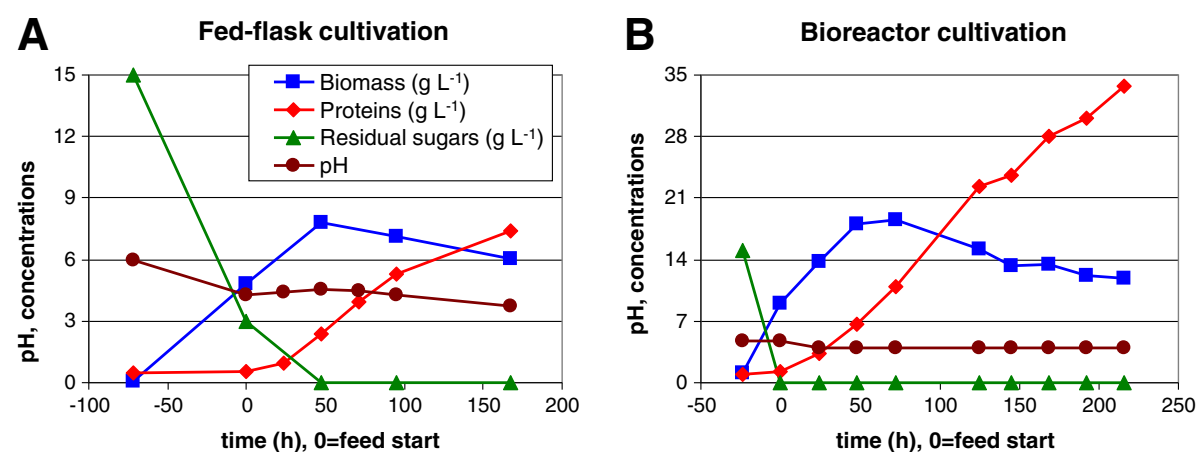

Figure 2 Monitoring examples for fed-flask and bioreactor cultivations. $\mathrm{pH}$ and concentrations were monitored during fed-flask cultivation (A) and bioreactor cultivation (B) during growth phase with excess glucose (time before $0 \mathrm{~h}$ ) then during protein production phase under carbon flux limitation (time after $0 \mathrm{~h}$ ) by feeding with a sugar mixture solution composed of 50\% lactose, 12.5\% xylose and 37.5\% glucose. In fed-flask protocol pH was stabilized owing to a stoichiometric mix of ammonia in the feed, whereas in bioreactor pH was controlled with ammonia pulses.

would imply that the overall mean value is a better predictor than the model, which was not the case here), and with standard deviations in the same range than the experimental ones observed during reproducibility assessment. In a mixture design, model terms values are hardly analysable directly since factors are not independent (their sum is constant). The effect of each sugar was better explained in contour plots representing the significant models.

\section{Effect of sugar mixture on production kinetics}

Figure 4 shows the effect of the fed sugar mixtures on the specific protein production rate measured in fed-flask protocol for both mixture designs with either lactose inducer (left) or cellobiose inducer (right).

The main effect was due to inducer content which increased the specific protein production rate. Lactose had a stronger effect than cellobiose (higher specific rate at high content in feed). However at an identical inducer content (horizontal line in Figure 1), specific protein production rate was higher when glucose was replaced by xylose (moving from right to left in each triangle). Therefore, xylose had a lower repressing effect on enzyme production than glucose.
Specific protein production rate was 5.5 to $11.5 \mathrm{mg}_{\mathrm{P}} \mathrm{g}_{\mathrm{X}}^{-1}$ $\mathrm{h}^{-1}$ with lactose as an inducer versus 5.5 to $8.9 \mathrm{mg}_{\mathrm{P}} \mathrm{g}_{\mathrm{X}}^{-1} \mathrm{~h}^{-1}$ for cellobiose. Thus, the $92 \%$ replacement of the inducer by a non-inducing sugar preserved at least $50 \%$ of the specific productivity.

\section{Effect of sugar mixture on cocktail characteristics}

The effects of the fed sugar mixtures on global enzymatic activities (cellulase and xylanase activities) are shown in Figure 5. For both activities, the inducer choice had little influence and the effects of sugar mixtures were similar for lactose and cellobiose inducers.

Low variations were observed for specific cellulase activity in the overall mixture design, with a 2 -fold variation $\left(0.33 \mathrm{IU} \mathrm{mg}_{\mathrm{P}}^{-1}\right.$ to $\left.0.69 \mathrm{IU} \mathrm{mg}_{\mathrm{P}}^{-1}\right)$. The main effect was due to xylose content in the feed which lowered cellulase activity. Surprisingly, glucose had beneficial effect and maximal cellulase activities were found when feedings were mostly-containing glucose (bottom right apex). Specific cellulase activity was slightly higher with lactose than with cellobiose as an inducer.

High variations were observed for specific xylanase activity, with a 6-fold variation (40 $\mathrm{IU} \mathrm{mg}_{\mathrm{P}}^{-1}$ to $260 \mathrm{IU} \mathrm{mg}_{\mathrm{P}}^{-1}$ ). Variations were only linked to xylose content. Specific xylanase activity increased linearly when xylose content

\section{Table 1 Reproducibility of the experimental design}

\begin{tabular}{|c|c|c|c|c|}
\hline Measurement & Unit & Mean value & Std. dev. & (RSD) \\
\hline Specific protein production rate & $m g_{p} g_{x}^{-1} h^{-1}$ & 11.9 & \pm 1.0 & $( \pm 9 \%)$ \\
\hline Specific cellulase activity & $I U m_{p}^{-1}$ & 0.47 & \pm 0.06 & $( \pm 10 \%)$ \\
\hline Specific xylanase activity & $\mathrm{IU} \mathrm{mg}_{\mathrm{p}}^{-1}$ & 130 & \pm 20 & $( \pm 16 \%)$ \\
\hline Specific endoglucanase activity & $\mathrm{IU} \mathrm{mg}_{\mathrm{P}}^{-1}$ & 11.2 & \pm 0.5 & $( \pm 4 \%)$ \\
\hline Specific Cel7A (CBH I) activity & $I U \mathrm{mg}_{\mathrm{P}}^{-1}$ & 0.23 & \pm 0.02 & $( \pm 8 \%)$ \\
\hline Specific $\beta$-glucosidase activity & $I U \mathrm{mg}_{\mathrm{p}}^{-1}$ & 0.52 & \pm 0.06 & $( \pm 10 \%)$ \\
\hline
\end{tabular}

The reproducibility of the whole experimental protocol (cell growth + protein production in fed-flask protocol + analyses) was assessed on the central point of the mixture design with lactose inducer (black circle Figure 1), by 10 repeats in 3 different series. 


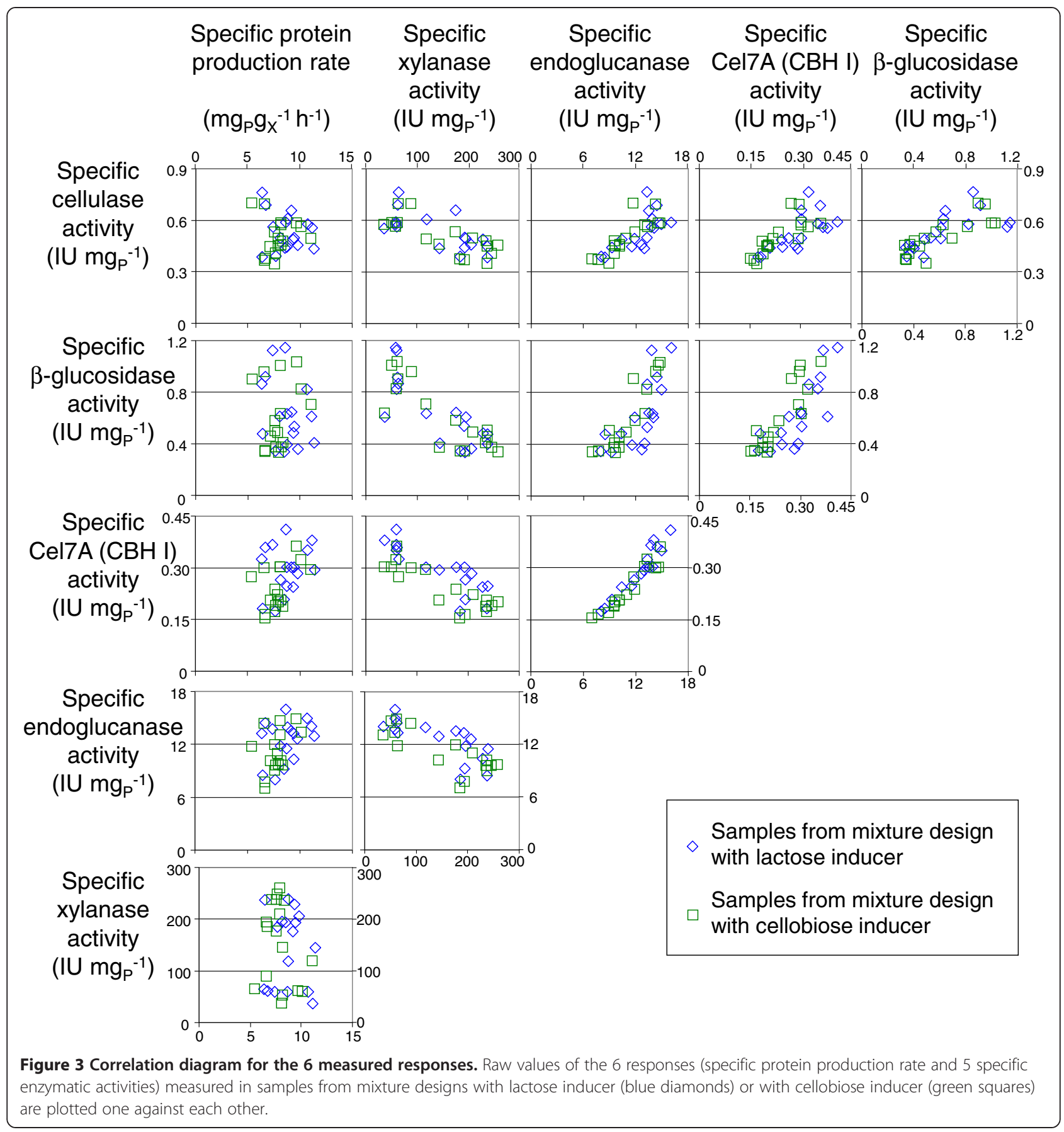

varied from 0 to $30 \%$, then was almost constant up to $92 \%$ xylose. Specific xylanase activity was slightly higher when using cellobiose rather than lactose as an inducer.

Figure 6 shows the effect of fed sugar mixtures on the three enzymatic activities needed to hydrolyse cellulose i.e. endoglucanase, cellobiohydrolase, and $\beta$-glucosidase. As observed for global cellulase activity, the effects of sugars were similar with each inducer. Enzymatic activities were however slightly higher with lactose than with cellobiose. Maximal variations were 2-fold for endoglucanase, 2.5-fold for cellobiohydrolase Cel7A (CBH I), and 4-fold for $\beta$-glucosidase. As for global cellulase activity, the main effect was due to xylose that lowered the three activities. In particular the specific activity of $\beta$-glucosidase was divided by two when xylose in the feed exceeded $30 \%$.

The maximum activity was reached for different substrate compositions: at high xylose content for xylanase, and at low xylose content for the four cellulolytic activities for which the maximum was reached at different glucose/ inducer ratio, depending also on the inducer choice. 


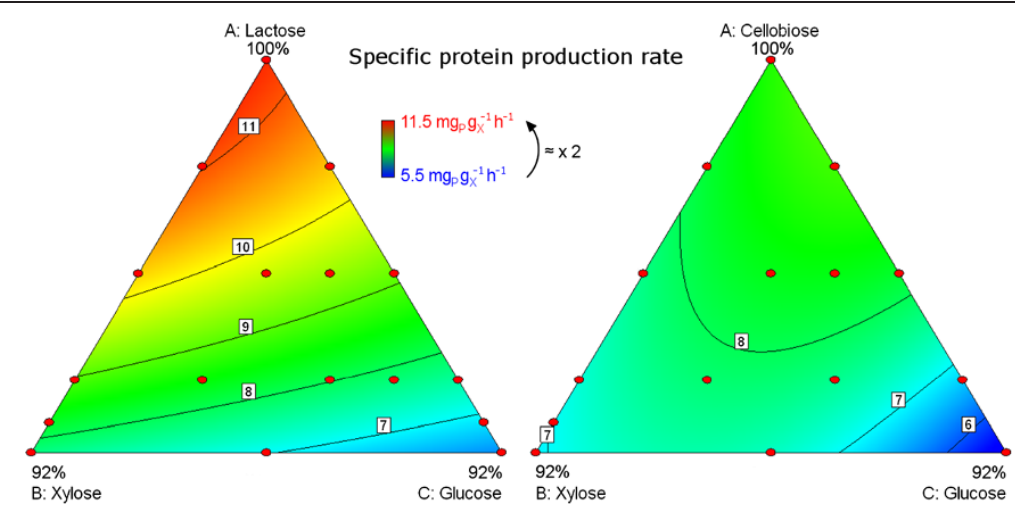

Figure 4 Effect of sugar mixtures on specific protein production rate. Specific protein production rate was measured during cellulase production with fed-batch process in fed-flask protocol for both mixture designs with lactose inducer (left) and cellobiose inducer (right) then modelled using a quadratic model (Additional file 1). Mixture compositions are shown in triangles according to Figure 1. Model values are in colour scale from blue (low values) to red (high values) according to the legend. Intermediate values are shown by contour lines (black lines). Red dots are experimental points used for the models.

Validation of the model by cultures in bioreactor

In order to validate the models obtained in fed-flask protocol, four cultivations were performed in bioreactors fed with distinct sugar mixtures. Since lactose had a higher inducing effect than cellobiose, the 4 feeding mixtures were supplemented with lactose (Figure 1). An example of $\mathrm{pH}$ and concentrations monitoring is shown in Figure 2 for a feed composed of 50\% lactose, 12.5\% xylose, $37.5 \%$ glucose. The six responses corresponding to the four bioreactor cultivations were compared to the model predictions (Figure 7).

Regarding the specific protein production rate (Figure 7A), the model accurately predicted the value for $100 \%$ lactose feeding, as previously observed [9]. Productivity for xylose-containing feeds was higher in bioreactor than the one predicted by the model, which is positive for scaling-up. Regarding global enzymatic activities (cellulase and xylanase, Figure $7 \mathrm{~B}$ and $\mathrm{C}$ ), the trends observed in bioreactor were consistent with those predicted by the models. The enzymatic activities were accurately predicted by the model for three conditions out of four. Regarding the three particular cellulase activities (Figure 7D to F), the models were appropriate to predict the enzymatic activities in bioreactor cultivation, especially for $\beta$ glucosidase activity (Figure 7F).

\section{Discussion}

\section{Efficiency of the design}

The fed-flask protocol used in this study allowed 34 fed-batch cultivations (plus 10 cultivations for reproducibility assessment), which would have been tedious in bioreactors, because cultivation is time-consuming (10 days). Since simple flasks were used, growth phases of a series could be performed in parallel with feeding phases of another series. Suitable reproducibility was obtained and cultivations in bioreactors validated the specific activities expected.

The lower specific protein production rate observed in fed-flask protocol may be due to diffusion or transfer issues which modified metabolism. Feeding rate was very low in fed-flask protocol so that feeding was not really continuous but rather intermittent, and mixing was less efficient. These combined effects may create higher local sugar concentrations which may result in lower protein induction.

The ranges of enzymatic activities obtained were higher in this study than previously reported, with 2 to 4- fold variations for cellulase activities versus $50 \%$ when comparing different lignocellulosic materials $[16,19]$. This may be due to the mixture design chosen, which allowed the comparison of much more different substrate compositions.

\section{Effect of inducer nature on enzyme secretion}

Surprisingly, similar patterns were observed for lactose and cellobiose inducers, although i) cellobiose was generally considered as a weaker inducer than lactose, and ii) lactose-induced cellulase involved lactose assimilation and metabolism of the resulting galactose moiety [27]. The lower cellulase production on cellobiose has generally been attributed to inhibitory actions such as catabolite repression by the glucose released from extracellular cellobiose hydrolysis [28], but this effect is negligible in glucose-derepressed strains like the one used in this study. Cellulase induction by cellobiose only occurred when its uptake was more favourable than extracellular hydrolysis [29], or when a di-glucoside permease with higher affinity than that of $\beta$-glucosidase was active [30]. Recently, intracellular $\beta$-glucosidases were shown to be involved in cellulase induction by cellobiose [31]. A similar mechanism was observed for cellulase induction by lactose, with probable involvement of a lactose permease [32]. In both cases, 

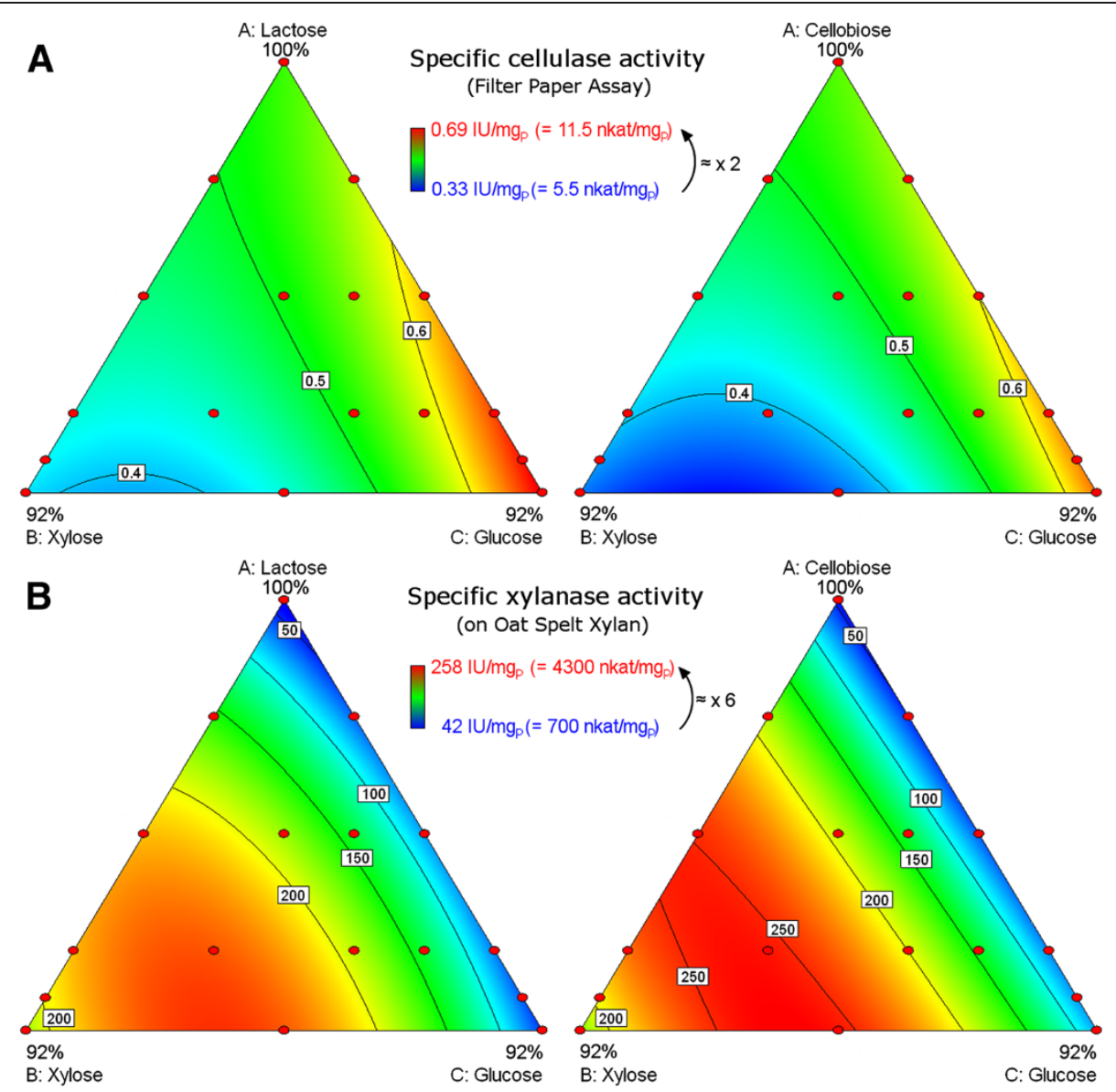

Figure 5 Effect of sugar mixtures on global enzymatic activities. Cellulase (A) and xylanase (B) activities were measured in final enzymatic cocktails produced in fed-flask protocol for mixture designs with either lactose inducer (left) or cellobiose inducer (right). They were modelled using a quadratic model (Additional file 1). Representation is identical to Figure 4.

inducer uptake was required for induction, which occurred preferentially under carbon flux limitation, as it was the case in this study. The differences in specific protein production rate between lactose and cellobiose may be due to differences in extracellular hydrolysis or uptake rates, which would modify the induction signal. In any case, the fact that similar enzymatic patterns were observed for cellobiose and lactose may indicate that, in a glucose de-repressed background, both compounds trigger a common induction mechanism.

\section{Correlations and incompatibilities between enzymatic activities}

High correlations were observed between the three particular cellulase activities, especially between endoglucanase and cellobiohydrolase activities (Figure 3). Since these activities are required for the complete cellulose hydrolysis, the coordinate regulation of these enzymes at transcriptional level is very likely [33]. In contrast, xylanase activity was negatively correlated with the four cellulolytic activities. At low specific growth rate, protein production was shown to be limited by secretion [34]. Therefore competition for secretion may occur between cellulase and xylanase enzymes.

Among the factors affecting the five studied activities, the xylose content was the main one. Xylose had a positive impact on xylanase activity but a negative impact on all the other cellulase activities. This result had previously been observed with lignocellulosic materials (pretreated or hydrolysed) $[12,16,19,22]$, but it was not clear whether sugar composition or occurrence of LCB degradation compounds prevailed. Our study showed that sugar composition accounted for the main effects. Therefore, the enzymatic composition of a cocktail can be predicted from any substrate using the models.

\section{Relevance of xylanase and $\beta$-glucosidase activities for hydrolysis}

Xylanase and $\beta$-glucosidase activities exhibited the highest variations, with a 6 -fold increase in xylanase activity correlated with a 4 -fold decrease of $\beta$-glucosidase activity. Accordingly, high levels of these two activities seemed rather 

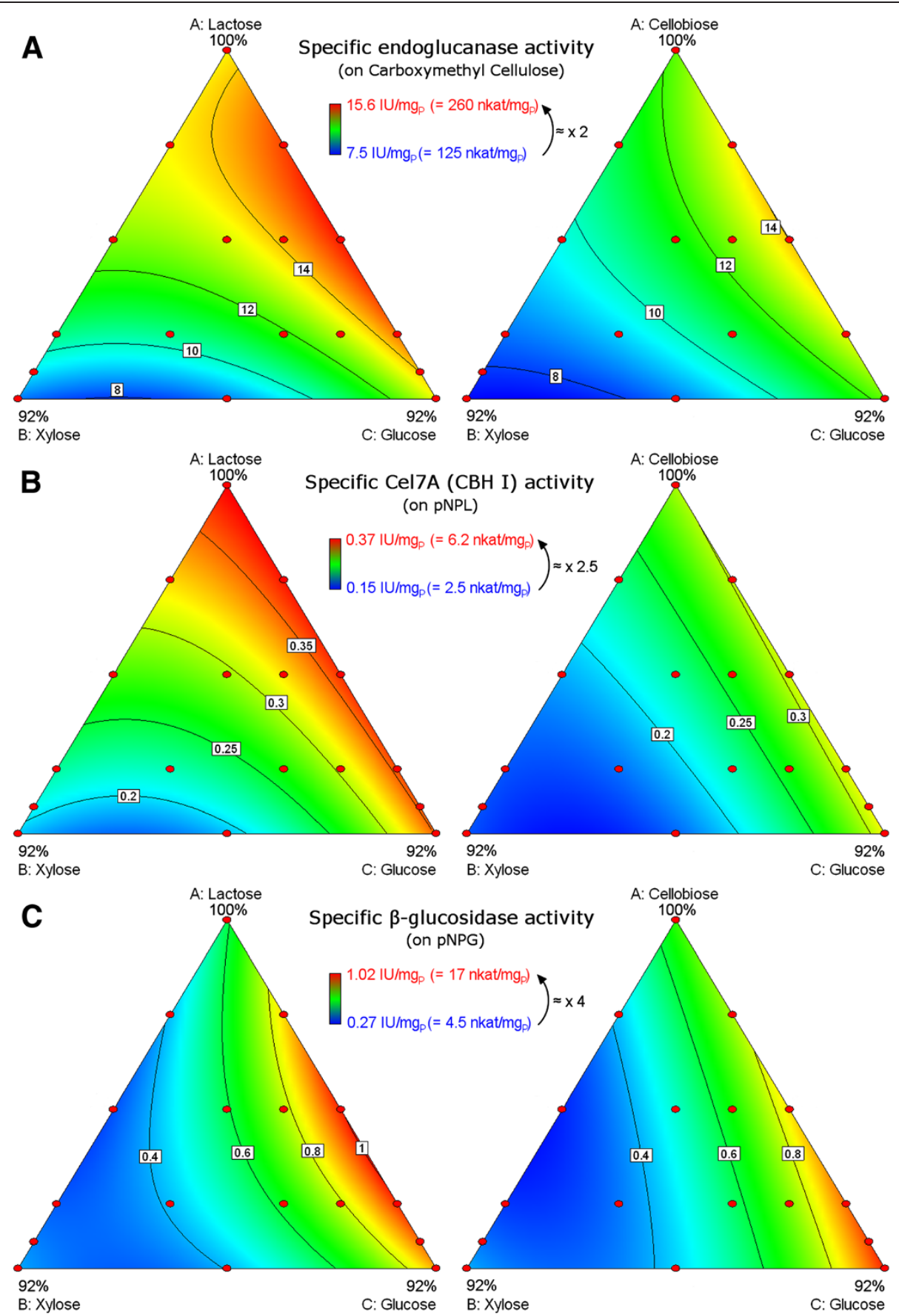

Figure 6 Effect of sugar mixtures on particular cellulolytic activities. Endoglucanase (A), cellobiohydrolase activity due to Cel7A(CBH I) (B), and B-glucosidase (C) were measured in final enzymatic cocktails produced in fed-flask protocol for both mixture designs with either lactose inducer (left) or cellobiose inducer (right) then modelled using a quadratic model (Additional file 1). Representation is identical to Figure 4.

incompatible in the enzymatic cocktails produced by T. reesei.

The importance of hemicellulase activities to improve LCB hydrolysis has been extensively studied in the last 5 years, either to understand biochemical mechanisms [35-44] or to design optimal enzyme mixtures [45-48]. All these studies concluded that hemicellulase activitiy had a beneficial effect on xylose and glucose release, the extent of the gains being highly dependent on the raw materials, the pretreatment and the hemicellulase activity.

Besides, the beneficial effect of $\beta$-glucosidase activity on cellulose hydrolysis has been shown for years. $\beta$ glucosidases are inhibited by the end-product glucose [49], and the $\beta$-glucosidase content is T. reesei enzymatic 


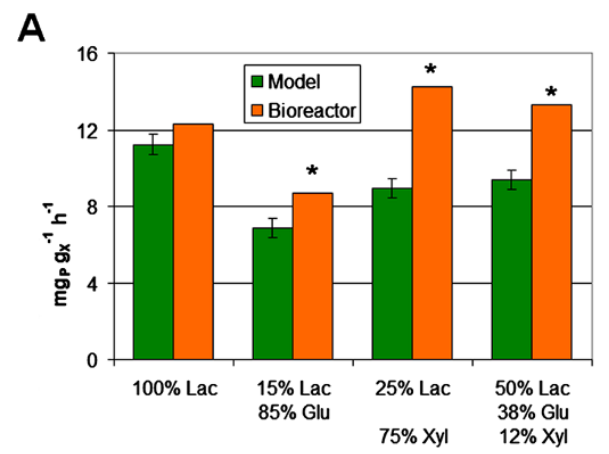

B

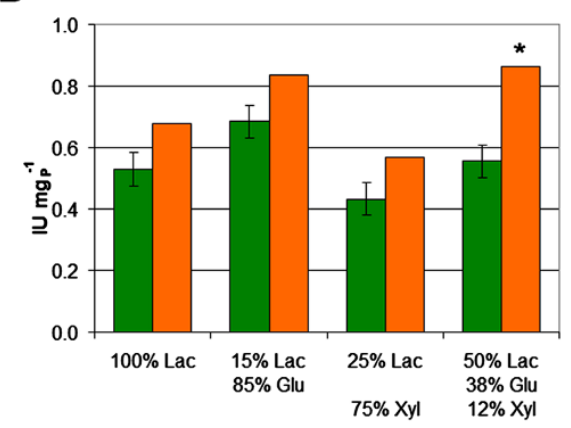

C

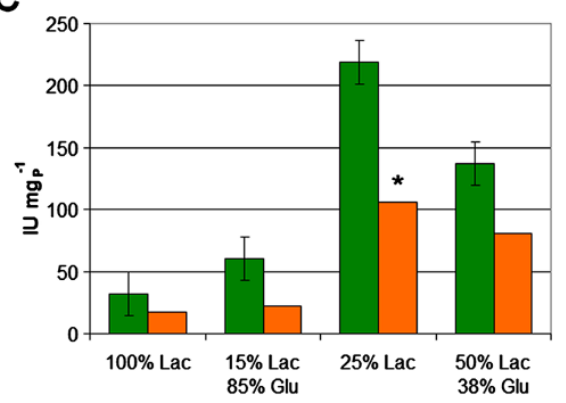

D

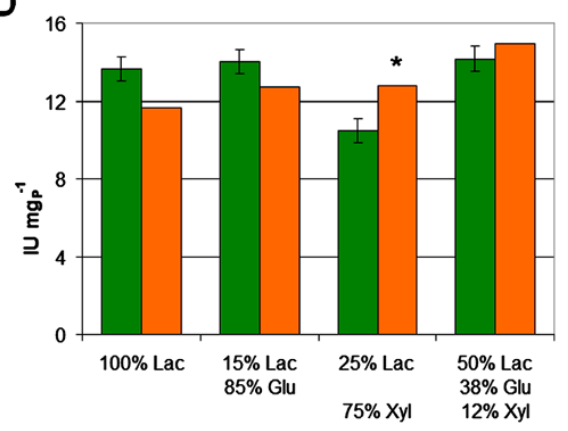

E

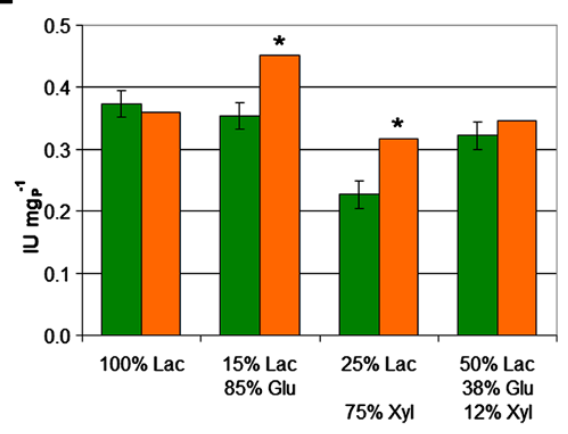

$\mathbf{F}$

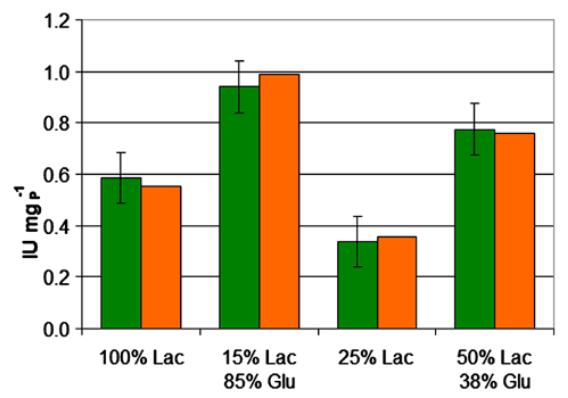

Figure 7 Models validation with bioreactor cultivations. Four fed-batch bioreactor cultivations, with 4 different feed compositions (on the abscissa), were performed to validate the models for (A) specific protein production rate, (B) specific cellulase activity, (C) specific xylanase activity, (D) specific endoglucanase activity, (E) specific Cel7A(CBH I) activity and (F) specific $\beta$-glucosidase activity. Green bars represent predicted values using models, and orange bars represent values from bioreactor cultivations. Error bars are models standard deviations. Stars indicate bioreactor values significantly different from the model (outside the prediction interval with 99\% confidence).

cocktails is often low [50], limiting the cellulose hydrolysis rate because of accumulation of cellobiose, a potent inhibitor of cellobiohydrolases.

If both activities are actually required for efficient LCB hydrolysis, a compromise will have to be reached in the choice of the substrate in order to get an optimal enzymatic cocktail. Since $\beta$-glucosidase content is very low in $T$. reesei cocktail, increasing $\beta$-glucosidase at the expense of xylanase activity will probably be the favourite choice for cellulase production, but it will limit the choice of the substrate feed composition.

With genetic and enzymatic engineering approaches, many work has been done to increase the $\beta$-glucosidase activity in $T$. reesei cocktail, by over-expressing the native $\beta$-glucosidase [51,52], heterologous $\beta$-glucosidases [53-56] including a highly improved $\beta$-glucosidase engineered by L-shuffling [57]. The resulting strains will probably have different enzymatic patterns, especially for $\beta$-glucosidase activity, which will modify the optimized substrate composition. Testing genetic engineered strains with similar experimental protocol may be very interesting to understand regulation effects in industrial-like fed-batch conditions.

\section{Conclusion}

The effect of sugar mixtures as a substrate for celluase production by a glucose-derepressed and cellulasehyperproducing mutant strain of $T$. reesei was assessed in simulated industrial fed-batch conditions. Owing to the miniaturized "fed-flask" protocol, 34 different mixtures were tested, for both inducers lactose and cellobiose. 
Enzymatic activity mappings were modelled and validated by bioreactor cultivations.

Using these models, the enzymatic composition of a cocktail can be predicted depending on the substrate composition, for example for xylose-rich hemicellulosic hydrolysates or glucose-rich cellulosic hydrolysates, and depending on inducer content. Conversely, these models can be used to choose the correct substrate composition for a desired enzymatic cocktail, to favour an enzymatic activity at the expense of an other, as it will be necessary for the incompatible xylanase and $\beta$-glucosidase activities.

\section{Methods}

\section{Strain and culture media}

T. reesei CL847 is a glucose-derepressed and cellulasehyperproducing strain obtained from QM 9414 strain by several steps of mutagenesis and selection, from Cayla Company, Toulouse, France [24]. Its behaviour and performances were comparable to other hyperproducer strains like e.g. Rut-C30 [14]. Spores were conserved in cryotubes at $-80^{\circ} \mathrm{C}$ with $50 \%$ glycerol.

Culture media for fed-flask protocol, preculture, and bioreactor cultivations were prepared according to [9].

\section{Fed-Flask cultivations}

Fed-flask cultivations were performed according to [9] with few modifications. A shared growth phase was performed each week for 8 fed-flasks. For each, 2 Fernbach flasks were prepared with $250 \mathrm{~mL}$ medium culture supplemented with $15 \mathrm{~g} \mathrm{~L}^{-1}$ glucose. Both flasks were inoculated with around $10^{6}$ spores then incubated at $30^{\circ} \mathrm{C}$ and $150 \mathrm{rpm}$ in an Infors rotary shaker. After $72 \mathrm{~h}$, the two flasks were mixed then split in 8 wide neck $250 \mathrm{~mL}$ Erlenmeyer flasks with $50 \mathrm{~mL}$ broth per flask. These flasks were incubated in the same conditions and fed at $0.3 \mathrm{~mL} \mathrm{~h}^{-1}$ average rate, using calibrated peristaltic pumps (Dasgip MP8) performing periodic additions at a rate close to $1 \mathrm{~mL} \mathrm{~h}^{-1}$. The feed solution composition was: total sugars $50 \mathrm{~g} \mathrm{~L}^{-1} ; \mathrm{NH}_{3} 20 \%$ (11 N) $15 \mathrm{~mL} \mathrm{~L}^{-1}$; $\left(\mathrm{NH}_{4}\right)_{2} \mathrm{SO}_{4} 0.8 \mathrm{~g} \mathrm{~L}^{-1}$. This composition was calculated from the stoichiometry of protein production to meet carbon, nitrogen and sulphur requirements, and stabilize $\mathrm{pH}[9]$.

\section{Bioreactor cultivations}

Bioreactor cultivations were carried out in Dasgip fedbatch-pro bioreactors with an initial working volume of $750 \mathrm{~mL}$. A shared preculture was performed in a Fernbach flask with $250 \mathrm{~mL}$ flask medium culture, inoculated with around $10^{6}$ spores, incubated $72 \mathrm{~h}$ at $150 \mathrm{rpm}$ and $30^{\circ} \mathrm{C}$ in an Infors rotary shaker, then split in four for the four bioreactors. Growth phase in batch was performed on $15 \mathrm{~g} \mathrm{~L}^{-1}$ glucose at $\mathrm{pH} 4.8$ and $27^{\circ} \mathrm{C}$ for $24 \mathrm{~h}$. Then fed-batch was performed at $\mathrm{pH} 4.0$ and $25^{\circ} \mathrm{C}$ with feeding at $2 \mathrm{~mL} \mathrm{~h}^{-1}$ by a $250 \mathrm{~g} \mathrm{~L}^{-1}$ mixed sugars solution. $\mathrm{pH}$ was automatically adjusted with $5.5 \mathrm{~N} \mathrm{NH}_{4} \mathrm{OH}$ solution. Aeration rate was fixed at $30 \mathrm{sL}$ $\mathrm{h}^{-1}$ and agitation was regulated to maintain dissolved oxygen at minimum $40 \%$ of its concentration at saturation.

\section{Analytical measurements}

Culture medium was filtrated using Whatman GF/C filters. For biomass concentration determination, biomass cake was washed with distilled water then dried at $105^{\circ} \mathrm{C}$ until constant weight.

Protein concentration was measured in supernatants against BSA standards $\left(0-1.5 \mathrm{~g} \mathrm{~L}^{-1}\right.$ range with secondorder regression) by Lowry method [58] using $D C^{\mathrm{me}}$ Protein Assay (Biorad). Lowry method has been recommended by IUPAC [25] and was shown consistent with carbon balance [9] for T. reesei cellulases.

Sugars concentration was measured by HPLC. Separation was carried out using Varian Metacarb 87P column with mobile phase milliQ water at $0.4 \mathrm{~mL} \mathrm{~min}^{-1}, 80^{\circ} \mathrm{C}$ and pressure around 32 bar; detection was carried out with Waters 2414 refractive index detector.

\section{Enzyme activity assays on complex polymeric substrates}

Reducing sugars released in enzymatic assays were measured with DNS reagent [59], by adding 1.5 or 2 volumes of DNS reagent in samples containing around $1 \mathrm{~g} / \mathrm{L}$ reducing sugars. The mix was boiled for 5 minutes then diluted with water to reach spectrophotometer linear range. Concentrations equivalents were calculated with a glucose scale by absorbance at $550 \mathrm{~nm}$ (global cellulase activity, endoglucanase activity) or with a xylose scale by absorbance at $540 \mathrm{~nm}$ (xylanase activity).

Global cellulase activity was measured using the IUPAC standard Filter Paper Assay [25], after a 15-fold miniaturization similar to [60] which allowed working in $2 \mathrm{~mL}$ Eppendorf tubes. In order to surround the desired $4 \%$ conversion yield, four enzyme dilutions were tested for each sample. This miniaturized protocol was validated by comparison with the standard IUPAC protocol.

Xylanase activity was measured according to IUPAC recommendations [26] on oat spelts xylan (Sigma) in $2 \mathrm{~mL}$ Eppendorf tubes. Hundred $\mu \mathrm{L}$ of $2 \%$ oat spelts xylan solution was mixed with $100 \mu \mathrm{L}$ sample dilution (both in $50 \mathrm{mM}$ pH 4.8 citrate buffer), and incubated 10 minutes at $50^{\circ} \mathrm{C}$ and $600 \mathrm{rpm}$ in Thermomixer (Eppendorf). Reducing sugars were revealed with $300 \mu \mathrm{L}$ DNS and 5 minutes boiling. Absorbance was measured at $540 \mathrm{~nm}$ after dilution with $1.5 \mathrm{~mL}$ water. Xylose equivalent concentration was calculated by comparison with a xylose scale, with subtraction of the xylose released in a substrate blank without enzyme. The measure was validated if enzymatic xylose release was in the linear range of the hydrolysis 
determined at first: below $6 \%$ conversion yield $(0.7 \mathrm{~g} / \mathrm{L}$ xylose concentration) in our experimental conditions.

Endoglucanase activity was measured according to IUPAC standard protocol on Carboxymethyl cellulose [25] after a 10-fold miniaturization which allowed working in $2 \mathrm{~mL}$ Eppendorf tubes. Incubation was performed in Thermomixer (Eppendorf) at $900 \mathrm{rpm}$. In order to surround the desired $0.5 \mathrm{~g} / \mathrm{L}$ glucose equivalent release, four enzyme dilutions were tested for each sample.

\section{Enzyme activity assays on chromogenic substrates}

Both cellobiohydrolase and $\beta$-glucosidase activities were measured on chromogenic substrates, $p$ NPL and $p$ NPG respectively, which release 4-nitrophenol ( $p \mathrm{NP})$. Assays were performed in $1.5 \mathrm{~mL}$ Eppendorf tubes, with $30 \mathrm{mi}$ nutes incubation at $50^{\circ} \mathrm{C}$.

Cellobiohydrolase activity due to $\mathrm{Cel} 7 \mathrm{~A}(\mathrm{CBH}$ I) was measured on $p$ NPL. Purified Cel6A (CBH II) has no activity on $p$ NPL (Y. Benoit and A. Margeot, personal communication). In our cocktails, we verified that around $90 \%$ of the activity on $p$ NPL was due to Cel7A by performing cellobiohydrolases inhibition with cellobiose. $50 \mu \mathrm{L} p \mathrm{NPL}$ solution at $3 \mathrm{mg} / \mathrm{mL}(6.5 \mathrm{mM})$ was mixed with $50 \mu \mathrm{L}$ sample dilution (both in citrate buffer $50 \mathrm{mM} \mathrm{pH} 4.8$ ).

$\beta$-glucosidase activity was measured on $p \mathrm{NPG}$, by mixing $90 \mu \mathrm{L} p \mathrm{NPG}$ solution at $1.5 \mathrm{mg} / \mathrm{mL}(4.8 \mathrm{mM})$ and $10 \mu \mathrm{L}$ sample dilution (both in citrate buffer $50 \mathrm{mM}$ $\mathrm{pH}$ 4.8).

In both cases, released $p \mathrm{NP}$ was revealed by adding $100 \mu \mathrm{L}$ of $2 \% \mathrm{Na}_{2} \mathrm{CO}_{3}$ solution. Absorbance was measured at $410 \mathrm{~nm}$ and released $p \mathrm{NP}$ concentration was calculated by comparison with a $p \mathrm{NP}$ scale from 25 to $200 \mu \mathrm{M}$. The measure was validated if released $p$ NP was in the scale range.

All enzymatic activities were expressed as specific activities in IU mg $\mathrm{P}_{\mathrm{P}}^{-1}$ ( IU meaning $\mu \mathrm{mol} \mathrm{min}^{-1}$ ) and converted in nkat $\mathrm{mg}_{\mathrm{P}}^{-1}$ in the figures legends $(1 \mathrm{nkat}=0.06 \mathrm{IU})$.

\section{Statistical analyses}

Mixture designs analyses were performed using Design Expert v8.0 (Stat-Ease, Inc.).

\section{Additional file}

Additional file 1: Terms values and statistical analyses for the 12 models. For each inducer and each response, the values for the 6 terms of the quadratic model are shown next to the statistical analyses of the model (predicted $R^{2}$, standard variation and $p$-value).

\footnotetext{
Abbreviations

LCB: Lignocellulosic biomass; pNP: 4-nitrophenol; pNPG: 4-nitrophenyl-ß-Dglucopyranoside; $p \mathrm{NPL}$ : 4-nitrophenyl- $\beta$-D-lactopyranoside; CMC: Carboxymethyl cellulose; RSD: Residual standard deviation; SPPR: Specific protein production rate.
}

\section{Competing interests}

The authors declare that they have no competing interests.

\section{Authors' contributions}

EJ and FBC designed the study. EJ carried out the experiments and drafted the manuscript. CC performed the bioreactor cultivations. FM supervised the study. CL and LP are academic supervisors of EJ. All authors revised, read and approved the final manuscript.

\section{Acknowledgements}

This study was part of Projet Futurol, a project supported by OSEO Innovation. We thank Rémy Marchal for proofreading of the manuscript.

\section{Author details}

${ }^{1}$ IFP Energies nouvelles, 1 et 4 avenue de Bois-Préau, 92852 Rueil-Malmaison, France. ${ }^{2}$ Clermont Université, Université Blaise Pascal, Labex IMobS3, Institut Pascal, Polytech Clermont-Ferrand, 24 av. des Landais, BP 20206, 63174 Aubière cedex, France.

Received: 22 March 2013 Accepted: 15 May 2013

Published: 17 May 2013

\section{References}

1. Aro N, Pakula TM, Penttila ME: Transcriptional regulation of plant cell wall degradation by filamentous fungi. FEMS Microbiol Rev 2005, 29:719-739.

2. Horn S, Vaaje-Kolstad G, Westereng B, Eijsink VG: Novel enzymes for the degradation of cellulose. Biotechnol Biofuels 2012, 5:45.

3. Singhania RR, Sukumaran RK, Patel AK, Larroche C, Pandey A: Advancement and comparative profiles in the production technologies using solid-state and submerged fermentation for microbial cellulases. Enzyme Microb Technol 2010, 46:541-549.

4. Barta Z, Kovacs K, Reczey K, Zacchi G: Process design and economics of on-site cellulase production on various carbon sources in a softwood-based ethanol plant. Enzyme Research 2010, 2010:734182.

5. Kazi FK, Fortman JA, Anex RP, Hsu DD, Aden A, Dutta A, Kothandaraman G: Techno-economic comparison of process technologies for biochemical ethanol production from corn stover. Fuel 2010, 89:S20-S28.

6. Klein-Marcuschamer D, Oleskowicz-Popiel P, Simmons BA, Blanch HW: The challenge of enzyme cost in the production of lignocellulosic biofuels. Biotechnol Bioeng 2012, 109:1083-1087.

7. Jourdier E, Ben Chaabane F, Poughon L, Larroche C, Monot F: Simple kinetic model of cellulase production by Trichoderma reesei for productivity or yield maximization. Chem Eng Trans 2012, 27:313-318.

8. Tolan J, Foody B: Cellulase from submerged fermentation. In Recent Progress in Bioconversion of Lignocellulosics. 65 th edition. Edited by Tsao G. Berlin: Springer; 1999:41-67.

9. Jourdier E, Poughon L, Larroche C, Monot F, Ben Chaabane F: A new stoichiometric miniaturization strategy for screening of industrial microbial strains: application to cellulase hyper-producing Trichoderma reesei strains. Microb Cell Fact 2012, 11:70.

10. Persson I, Tjerneld F, Hahn-Hägerdal B: Fungal cellulolytic enzyme production: a review. Process Biochem 1991, 26:65-74.

11. Pourquié J, Warzywoda M, Chevron F, Thery D, Lonchamp D, Vandecasteele JP: Scale up of cellulase production and utilization. In FEMS Symposium n 43 : Biochemistry and Genetics of Cellulose Degradation. Edited by Aubert J-P, Beguin P, Millet J. London: Academic Press; 1988:71-86.

12. Warzywoda M, Larbre E, Pourquié J: Production and characterization of cellulolytic enzymes from Trichoderma reesei grown on various carbon sources. Bioresour Technol 1992, 39:125-130.

13. Philippidis GP: Cellulase production technology. In Enzymatic Conversion of Biomass for Fuels Production. 566th edition. Edited by Himmel M, Baker JO, Overend RP. Washington, DC: American Chemical Society; 1994:188-217.

14. Esterbauer H, Steiner W, Labudova I, Hermann A, Hayn M: Production of Trichoderma cellulase in laboratory and pilot scale. Bioresour Technol 1991, 36:51-65.

15. Dashtban M, Maki M, Leung KT, Mao C, Qin W: Cellulase activities in biomass conversion: measurement methods and comparison. Crit Rev Biotechnol 2010, 30:302-309.

16. Juhasz T, Szengyel Z, Reczey K, Siika-Aho M, Viikari L: Characterization of cellulases and hemicellulases produced by Trichoderma reesei on various carbon sources. Process Biochem 2005, 40:3519-3525. 
17. Jun $H$, Kieselbach $T$, Jonsson $L$ : Enzyme production by filamentous fungi: analysis of the secretome of Trichoderma reesei grown on unconventional carbon source. Microb Cell Fact 2011, 10:68.

18. Olsson L, Christensen T, Hansen KP, Palmqvist EA: Influence of the carbon source on production of cellulases, hemicellulases and pectinases by Trichoderma reesei Rut C-30. Enzyme Microb Technol 2003, 33:612-619.

19. Sipos B, Benko Z, Dienes D, Reczey K, Viikari L, Siika-Aho M: Characterisation of specific activities and hydrolytic properties of cell-wall-degrading enzymes produced by Trichoderma reesei Rut C30 on different carbon sources. Appl Biochem Biotechnol 2010, 161:347-364.

20. Xiong $\mathrm{H}$, Turunen $\mathrm{O}$, Pastinen O, Leisola M, von Weymarn N: Improved xylanase production by Trichoderma reesei grown on L-arabinose and lactose or D-glucose mixtures. App/ Microbiol Biotechnol 2004, 64:353-358.

21. Xiong HR, von Weymarn N, Turunen O, Leisola M, Pastinen O: Xylanase production by Trichoderma reesei Rut C-30 grown on L-arabinose-rich plant hydrolysates. Bioresour Technol 2005, 96:753-759

22. Ballerini D, Desmarquest JP, Pourquié J, Nativel F, Rebeller M: Ethanol production from Lignocellulosics: large scale experimentation and economics. Bioresour Technol 1994, 50:17-23.

23. Ike M, Park JY, Tabuse M, Tokuyasu K: Controlled preparation of cellulases with xylanolytic enzymes from Trichoderma reesei (Hypocrea jecorina) by continuous-feed cultivation using soluble sugars. Biosci Biotechnol Biochem 2013, 77:161-166.

24. Durand H, Clanet M, Tiraby G: Genetic improvement of Trichoderma reesei for large scale cellulase production. Enzyme Microb Technol 1988, 10:341-346.

25. Ghose TK: Measurement of cellulase activities. Pure Appl Chem 1987, 59:257-268.

26. Ghose TK, Bisaria VS: Measurement of hemicellulase activities - Part 1: Xylanases. Pure Appl Chem 1987, 59:1739-1752.

27. Seiboth B, Herold S, Kubicek CP: Metabolic engineering of inducer formation for cellulase and hemicellulase gene expression in Trichoderma reesei. In Reprogramming Microbial Metabolic Pathways. 64th edition. Edited by Wang X, Chen J, Quinn P. Netherlands: Springer; 2012:367-390.

28. Mandels M, Reese ET: Induction of cellulase in fungi by cellobiose. J Bacteriol 1960, 79:816-826.

29. Fritscher C, Messner R, Kubicek CP: Cellobiose metabolism and cellobiohydrolase I biosynthesis by Trichoderma reesei. Exp Mycol 1990 14:405-415

30. Kubicek CP, Messner R, Gruber F, Mandels M, Kubicek-Pranz EM: Triggering of cellulase biosynthesis by cellulose in Trichoderma reesei. Involvement of a constitutive, sophorose-inducible, glucose-inhibited beta-diglucoside permease. J Biol Chem 1993, 268:19364-19368.

31. Zhou Q, Xu J, Kou Y, Lv X, Zhang X, Zhao G, Zhang W, Chen G, Liu W: Differential involvement of beta-Glucosidases from Hypocrea jecorina in rapid induction of cellulase genes by cellulose and cellobiose. Eukaryot Cell 2012, 11:1371-1381.

32. Morikawa Y, Ohashi T, Mantani O, Okada H: Cellulase induction by lactose in Trichoderma reesei PC-3-7. Appl Microbiol Biotechnol 1995, 44:106-111.

33. IImen M, Saloheimo A, Onnela ML, Penttila ME: Regulation of cellulase gene expression in the filamentous fungus Trichoderma reesei. Appl Environ Microbiol 1997, 63:1298-1306.

34. Pakula TM, Salonen K, Uusitalo J, Penttila ME: The effect of specific growth rate on protein synthesis and secretion in the filamentous fungus Trichoderma reesei. Microbiology 2005, 151:135-143.

35. Bura R, Chandra R, Saddler J: Influence of xylan on the enzymatic hydrolysis of steam-pretreated corn stover and hybrid poplar. Biotechnol Prog 2009, 25:315-322.

36. Hu J, Arantes V, Saddler J: The enhancement of enzymatic hydrolysis of lignocellulosic substrates by the addition of accessory enzymes such as xylanase: is it an additive or synergistic effect? Biotechnol Biofuels 2011, 4:36.

37. Zhang J, Tang M, Viikari L: Xylans inhibit enzymatic hydrolysis of lignocellulosic materials by cellulases. Bioresour Technol 2012, 121:8-12.

38. Benko Z, Siika-Aho M, Viikari L, Reczey K: Evaluation of the role of xyloglucanase in the enzymatic hydrolysis of lignocellulosic substrates. Enzyme Microb Technol 2008, 43:109-114.

39. Kumar R, Wyman CE: Effects of cellulase and xylanase enzymes on the deconstruction of solids from pretreatment of poplar by leading technologies. Biotechnol Prog 2009, 25:302-314.

40. Shi J, Ebrik MA, Yang B, Garlock RJ, Balan V, Dale BE, Ramesh Pallapolu V, Lee $Y$ Y, Kim Y, Mosier NS, Ladisch MR, Holtzapple MT, Falls M, Sierra-Ramirez R, Donohoe BS, Vinzant TB, Elander RT, Hames B, Thomas S, Warner RE,
Wyman CE: Application of cellulase and hemicellulase to pure xylan, pure cellulose, and switchgrass solids from leading pretreatments. Bioresour Technol 2011, 102:11080-11088.

41. Qing Q, Wyman CE: Hydrolysis of different chain length xylooliogmers by cellulase and hemicellulase. Bioresour Technol 2011, 102:1359-1366.

42. Qing Q, Yang B, Wyman CE: Xylooligomers are strong inhibitors of cellulose hydrolysis by enzymes. Bioresour Technol 2010, 101:9624-9630.

43. Qing Q, Wyman C: Supplementation with xylanase and beta-xylosidase to reduce xylo-oligomer and xylan inhibition of enzymatic hydrolysis of cellulose and pretreated corn stover. Biotechnol Biofuels 2011, 4:18.

44. Penttilä PA, Várnai A, Pere J, Tammelin T, Salmén L, Siika-aho M, Viikari L, Serimaa R: Xylan as limiting factor in enzymatic hydrolysis of nanocellulose. Bioresour Technol 2013, 129:135-141.

45. Várnai A, Huikko L, Pere J, Siika-aho M, Viikari L: Synergistic action of xylanase and mannanase improves the total hydrolysis of softwood. Bioresour Technol 2011, 102:9096-9104.

46. Gao D, Uppugundla N, Chundawat S, Yu X, Hermanson S, Gowda K, Brumm $P$, Mead D, Balan V, Dale B: Hemicellulases and auxiliary enzymes for improved conversion of lignocellulosic biomass to monosaccharides. Biotechnol Biofuels 2011, 4:5

47. Billard H, Faraj A, Lopes Ferreira N, Menir S, Heiss-Blanquet S: Optimization of a synthetic mixture composed of major Trichoderma reesei enzymes for the hydrolysis of steam-exploded wheat straw. Biotechnol Biofuels 2012, 5:9.

48. Banerjee G, Car S, Scott-Craig JS, Borrusch MS, Walton JD: Rapid optimization of enzyme mixtures for deconstruction of diverse pretreatment/biomass feedstock combinations. Biotechnol Biofuels 2010, 3:22.

49. Singhania RR, Patel AK, Sukumaran RK, Larroche C, Pandey A: Role and significance of beta-glucosidases in the hydrolysis of cellulose for bioethanol production. Bioresour Technol 2013, 127:500-507.

50. Herpoel-Gimbert I, Margeot A, Dolla A, Jan G, Molle D, Lignon S, Mathis H, Sigoillot JC, Monot F, Asther M: Comparative secretome analyses of two Trichoderma reesei RUT-C30 and CL847 hypersecretory strains. Biotechnol Biofuels 2008, 1:18.

51. Rahman Z, Shida Y, Furukawa T, Suzuki Y, Okada H, Ogasawara W, Morikawa Y: Application of Trichoderma reesei cellulase and xylanase promoters through homologous recombination for enhanced production of extracellular betaglucosidase i. Biosci Biotechnol Biochem 2009, 73:1083-1089.

52. Zhang J, Zhong Y, Zhao X, Wang T: Development of the cellulolytic fungus Trichoderma reesei strain with enhanced beta-glucosidase and filter paper activity using strong artifical cellobiohydrolase 1 promoter. Bioresour Technol 2010, 101:9815-9818.

53. Wang B, Xia L: High efficient expression of cellobiase gene from Aspergillus niger in the cells of Trichoderma reesei. Bioresour Technol 2011 102:4568-4572.

54. Nakazawa H, Kawai T, Ida N, Shida Y, Kobayashi Y, Okada H, Tani S, Sumitani J, Kawaguchi T, Morikawa Y, Ogasawara W: Construction of a recombinant Trichoderma reesei strain expressing Aspergillus aculeatus beta-glucosidase 1 for efficient biomass conversion. Biotechnol Bioeng 2012, 109:92-99.

55. Ma L, Zhang J, Zou G, Wang C, Zhou Z: Improvement of cellulase activity in Trichoderma reesei by heterologous expression of a beta-glucosidase gene from Penicillium decumbens. Enzyme Microb Technol 2011, 49:366-371.

56. Dashtban M, Qin W: Overexpression of an exotic thermotolerant beta-glucosidase in trichoderma reesei and its significant increase in cellulolytic activity and saccharification of barley straw. Microb Cell Fact 2012, 11:63

57. Ayrinhac C, Margeot A, Ferreira NL, Ben Chaabane F, Monot F, Ravot G, Sonet JM, Fourage L: Improved saccharification of wheat straw for biofuel production using an Engineered Secretome of Trichoderma reesei. Org Process Res Dev 2011, 15:275-278

58. Lowry OH, Rosebrough NJ, Farr AL, Randall RJ: Protein measurement with the Folin phenol reagent. J Biol Chem 1951, 193:265-275.

59. Miller $G L$ : Use of dinitrosalicylic acid reagent for determination of reducing sugar. Anal Chem 1959, 31:426-428.

60. Xiao Z, Storms R, Tsang A: Microplate-based filter paper assay to measure total cellulase activity. Biotechnol Bioeng 2004, 88:832-837.

doi:10.1186/1754-6834-6-79

Cite this article as: Jourdier et al:: Cellulase activity mapping of Trichoderma reesei cultivated in sugar mixtures under fed-batch conditions. Biotechnology for Biofuels 2013 6:79. 